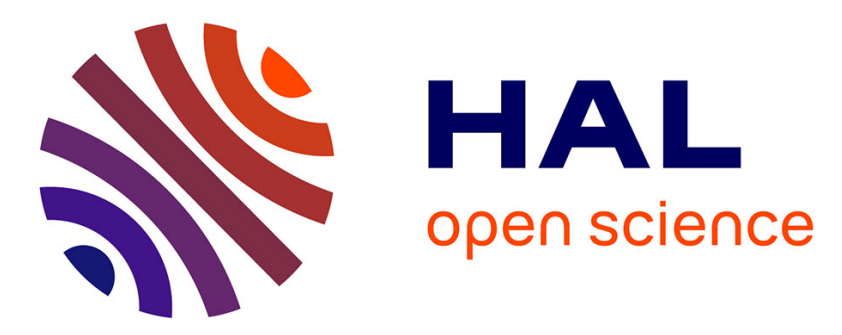

\title{
KxNa1-xNbO3 perovskite thin films grown by pulsed laser deposition on R-plane sapphire for tunable microwave devices
}

\author{
Barthélemy Aspe, Fatou Cissé, Xavier Castel, Valérie Demange, Stéphanie \\ Députier, Sophie Ollivier, Valérie Bouquet, Loïc Joanny, Ronan Sauleau, \\ Maryline Guilloux-Viry
}

\section{To cite this version:}

Barthélemy Aspe, Fatou Cissé, Xavier Castel, Valérie Demange, Stéphanie Députier, et al.. KxNa1xNbO3 perovskite thin films grown by pulsed laser deposition on R-plane sapphire for tunable microwave devices. Journal of Materials Science, 2018, 53 (18), pp.13042 - 13052. 10.1007/s10853-0182593-9 . hal-01825990

\author{
HAL Id: hal-01825990 \\ https://hal.science/hal-01825990
}

Submitted on 14 Sep 2018

HAL is a multi-disciplinary open access archive for the deposit and dissemination of scientific research documents, whether they are published or not. The documents may come from teaching and research institutions in France or abroad, or from public or private research centers.
L'archive ouverte pluridisciplinaire HAL, est destinée au dépôt et à la diffusion de documents scientifiques de niveau recherche, publiés ou non, émanant des établissements d'enseignement et de recherche français ou étrangers, des laboratoires publics ou privés. 


\title{
$\mathrm{K}_{x} \mathrm{Na}_{1-x} \mathrm{NbO}_{3}$ perovskite thin films grown by pulsed laser deposition
}

\section{on R-plane sapphire for tunable microwave devices}

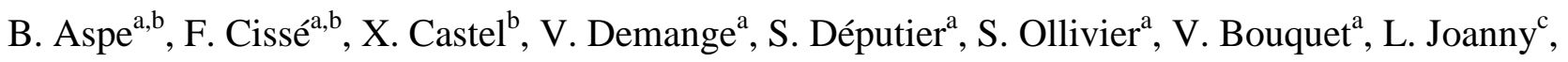
R. Sauleau ${ }^{\mathrm{b}}$, M. Guilloux-Viry ${ }^{\mathrm{a}, \mathrm{c}}$

\author{
${ }^{\mathrm{a}}$ Univ Rennes, CNRS, ISCR - UMR 6226, F-35000 Rennes, France \\ ${ }^{\mathrm{b}}$ Univ Rennes, CNRS, IETR - UMR 6164, F-35000 Rennes, France \\ c Univ Rennes, CNRS, ScanMAT - UMS 2001 F-35000 Rennes, France
}

corresponding authors:

Barthélemy Aspe: email adress: barthelemy.aspe@univ-rennes1.fr

ORCID identifier: 0000-0001-8927-4013

phone number: +33 (0) 223236570

Maryline Guilloux-Viry: email adress: maryline.guilloux-viry@univ-rennes1.fr

ORCID identifier: 0000-0001-7773-1643

phone number: +33 (0) 223235655

\section{$\underline{\text { Abstract }}$}

$\mathrm{K}_{x} \mathrm{Na}_{1-x} \mathrm{NbO}_{3}$ thin films with $x=0.5$ and $x=0.7$ were deposited by pulsed laser deposition onto R-cut sapphire substrates to be suitable for microwave applications. The $500-800$ nm-thick films present a preferential (100) orientation. The $\omega$-scans show a weak mosaicity (full-width-athalf-maximum equal to $0.36^{\circ}$ and $0.60^{\circ}$ for $x=0.5$ and $x=0.7$, respectively). In addition to this texture, the in-plane ordering evidenced by X-ray diffraction $\varphi$-scan for the (100) orientation is in agreement with an epitaxial-like growth in spite of the high lattice mismatch between $\mathrm{K}_{x} \mathrm{Na}_{1-x} \mathrm{NbO}_{3}$ and sapphire. The dielectric characteristics and the frequency tunability at microwave frequencies were obtained from coplanar waveguide devices (transmission lines and stub resonators). For the $\mathrm{K}_{0.5} \mathrm{Na}_{0.5} \mathrm{NbO}_{3}$ and $\mathrm{K}_{0.7} \mathrm{Na}_{0.3} \mathrm{NbO}_{3}$ compositions, high dielectric permittivity $\varepsilon_{r}$ values of 360 and 
250, and loss tangent $\tan \delta$ values of 0.36 and 0.43 without biasing were retrieved from the transmission lines measurements at $10 \mathrm{GHz}$, respectively. Frequency tunabilities of $15 \%$ and $12 \%$ have been assessed under $80 \mathrm{kV} / \mathrm{cm}$ biasing from stub resonator measurements for the $\mathrm{K}_{0.5} \mathrm{Na}_{0.5} \mathrm{NbO}_{3}$ and $\mathrm{K}_{0.7} \mathrm{Na}_{0.3} \mathrm{NbO}_{3}$ compositions, respectively. $\mathrm{K}_{0.5} \mathrm{Na}_{0.5} \mathrm{NbO}_{3}$ composition is therefore a promising solution for miniaturized tunable devices at microwave frequencies.

Keywords: ferroelectrics; thin films; tunable devices; microwave frequencies.

\section{Introduction}

From the last decade, a great interest is devoted to multifunctional oxides that present a wide range of properties, and offer new opportunities in the development of efficient devices. In this frame, ferroelectric materials, which exhibit also piezoelectric behavior, have been extensively studied due to their numerous applications in sensors, micro-electro-mechanical systems (MEMS) and memory devices [1-4]. Nowadays, wireless applications require advanced miniature and tunable microwave devices [5-7]. Besides the standard reconfigurable devices based on radiofrequency micro-electro-mechanical systems (RF-MEMS) or solid-state components, integration of ferroelectric materials brings an alternative solution. Indeed ferroelectric thin films exhibit a high dielectric permittivity $\varepsilon_{r}$ which can be controlled by an external static electric field, promoting both miniaturized and reconfigurable microwave devices. Besides the most popular ferroelectric materials, namely $\mathrm{Ba}_{x} \mathrm{Sr}_{1-x} \mathrm{Ti}_{x} \mathrm{O}_{3}$ (BST) [8, 9] and $\mathrm{PbZr}_{1-x} \mathrm{Ti}_{x} \mathrm{O}_{3}$ (PZT) [10, 11], the lead-free potassium niobate family presents relevant features [12-14].

Currently, among the lead-free ferroelectric materials, a specific attention is paid to the perovskite-type oxide $\mathrm{K}_{x} \mathrm{Na}_{1-x} \mathrm{NbO}_{3}(\mathrm{KNN})$. The $\mathrm{KNN}$ compositions belong to a solid solution between the ferroelectric $\mathrm{KNbO}_{3}$ (orthorhombic, space group (SG): Bmm2, JCPDS file \# 01-0712171) and the antiferroelectric $\mathrm{NaNbO}_{3}$ (orthorhombic, SG: $P 2_{1} m a$, JCPDS file \# 01-077-0873) [15, 16]. Through the solid-solution, the KNN compounds present various crystalline symmetries. Only 
$2 \%$ atomic of $\mathrm{K}$ is sufficient to modify the structure of $\mathrm{NaNbO}_{3}$ [17]. At room temperature, for $x$ lying between 0.48 and 0.83 , the KNN compounds have a primitive monoclinic cell with $a_{\mathrm{m}} \approx c_{m} \approx$ $4 \AA>b_{\mathrm{m}}$, and $\beta$ slightly higher than $90^{\circ}$. The phases can also be described by a larger A-centered orthorhombic cell (i.e. $a_{0} \approx c_{0} \approx 4 \sqrt{2} \AA$ ) $[18,19]$. Tellier et al. and Handoko et al. have shown that the lattice parameters $a_{\mathrm{m}}$ and $c_{m}$ increase with the potassium content. This increase is explained by the larger $\mathrm{K}^{+}$radius $\left(1.33 \AA\right.$ ) against the $\mathrm{Na}^{+}$one $(0.97 \AA)$ [18, 19].

The KNN oxide exhibits (i) high Curie temperature $\left(T_{c} \approx 400^{\circ} \mathrm{C}\right)$ depending upon its composition [17, 20], (ii) high values of dielectric permittivity $\varepsilon_{r}$ (between 100 and 500 at $100 \mathrm{kHz}$ [15]), and (iii) high piezoelectric coefficient $d_{33}$ (up to $300 \mathrm{pC} / \mathrm{N}$ [21]). This range in $T_{c}$ value is valuable to ensure the strong thermal stability of the targeted microwave devices operating at room temperature. Recent studies were reported at microwave frequencies on KNN ceramics and thin films [22-26]. As expected, the dielectric permittivity varies according to the bulk composition from $\varepsilon_{r}=92$ for $\mathrm{K}_{0.2} \mathrm{Na}_{0.8} \mathrm{NbO}_{3}$ to $\varepsilon_{r}=124$ for $\mathrm{K}_{0.5} \mathrm{Na}_{0.5} \mathrm{NbO}_{3}$ at $10 \mathrm{GHz}$ [23]. On one hand, Peddigari et al. reported values of $\varepsilon_{r}=287$ and loss tangent $\tan \delta=0.01$ at $10 \mathrm{GHz}$ on $\mathrm{K}_{0.5} \mathrm{Na}_{0.5} \mathrm{NbO}_{3}$ thin films [25]. On the other hand, Kim et al. reported the value $\tan \delta=0.23$ at $20 \mathrm{GHz}$ on $\mathrm{K}_{0.5} \mathrm{Na}_{0.5} \mathrm{NbO}_{3}$ thin films ( $\varepsilon_{\mathrm{r}}$ value not available) with a capacitance tunability of $22 \%$ at $20 \mathrm{GHz}$ under an external biasing field $E_{\text {bias }}=200 \mathrm{kV} / \mathrm{cm}$ [26]. According to these preliminary studies, compositions with the lowest potassium/sodium ratio are not identified as promising candidates for microwave applications. This explains why the $\mathrm{K}_{0.5} \mathrm{Na}_{0.5} \mathrm{NbO}_{3}$ composition has been first selected here. Moreover, its proximity with the reported morphotropic phase boundary [27], defined as continuous-phase transitions between two crystalline structures, augurs well for interesting ferroelectric properties at microwave frequencies [28]. A second composition with a higher potassium/sodium ratio $\left(\mathrm{K}_{0.7} \mathrm{Na}_{0.3} \mathrm{NbO}_{3}\right)$ has also been studied here.

The main objective of the present work is to investigate the microwave response of tunable devices based on KNN thin films. Two compositions $\mathrm{K}_{0.5} \mathrm{Na}_{0.5} \mathrm{NbO}_{3}$ and $\mathrm{K}_{0.7} \mathrm{Na}_{0.3} \mathrm{NbO}_{3}$ were 
investigated in detail. The microstructure and the crystalline characteristics of the thin films grown by pulsed laser deposition on R-plane sapphire substrates were determined and the related KNNbased tunable device performances at microwave frequencies were compared.

\section{Experimental details}

2.1. Elaboration of KNN thin films by pulsed laser deposition (PLD)

The ceramic targets were prepared from KNN powders first synthesized by a solid state reaction at $940^{\circ} \mathrm{C}$ for 4 hours in air from sodium carbonate $\mathrm{Na}_{2} \mathrm{CO}_{3}$ (RP NORMAPUR 99.8\%), anhydrous potassium carbonate $\mathrm{K}_{2} \mathrm{CO}_{3}$ (ACROS Organics $99 \%$ ) and niobium oxide $\mathrm{Nb}_{2} \mathrm{O}_{5}$ (Alfa Aesar 99.5\%) powders mixed in a planetary ball-mill for 1 hour at a 400 rotations per minute speed (PM100, Retsch). In a second step, the powders were K-enriched with a potassium nitrate $\mathrm{KNO}_{3}$ powder, to balance the loss of potassium during the laser deposition due to its volatility. Afterwards the powders were uniaxially pressed into 25 mm-diameter targets and annealed up to $500^{\circ} \mathrm{C}$ in air for 3 hours.

The KNN thin films were deposited by the pulsed laser deposition (PLD) technique from two KNN targets. By controlling the K/Na ratio of the home-made targets, two thin film compositions were prepared: $\mathrm{K}_{0.5} \mathrm{Na}_{0.5} \mathrm{NbO}_{3}(\mathrm{KNN} 50 / 50)$ and $\mathrm{K}_{0.7} \mathrm{Na}_{0.3} \mathrm{NbO}_{3}(\mathrm{KNN70/30)}$. Each thin film was grown on R-plane sapphire $(1 \overline{1} 02) \mathrm{Al}_{2} \mathrm{O}_{3}(10 \mathrm{~mm} \times 10 \mathrm{~mm} \times 0.5 \mathrm{~mm})$ single crystal previously cleaned in acetone and isopropanol ultrasonic baths for 5 min each. Despite the strong mismatch with the perovskite-like structures, sapphire substrate fits well within microwave applications, thanks to its convenient dielectric characteristics $\left(\varepsilon_{r} \approx 10\right.$ and $\tan \delta \approx 10^{-4}$ at $10 \mathrm{GHz}$ and room temperature). Moreover sapphire substrate is highly stable in air and moisture atmosphere, then well suitable for further lithography and wet etching processes. A KrF excimer laser (Coherent company, pulse duration $20 \mathrm{~ns}, \lambda=248 \mathrm{~nm}$ ) set at an energy of $210 \mathrm{~mJ}$, a fluence of 2-3 J.cm ${ }^{-2}$ and a $4 \mathrm{~Hz}$ working frequency, was used to ablate the KNN ceramic targets. The KNN films were grown onto 
sapphire substrates heated at $650^{\circ} \mathrm{C}$ and located at $55 \mathrm{~mm}$ in front of the selected target, under a 0.3 mbar oxygen pressure. The expected deposition rate being close to $15 \mathrm{~nm} / \mathrm{min}$, a deposition time of 40 minutes was used to obtain a thin film thickness of about $600 \mathrm{~nm}$.

\subsection{KNN thin film characterizations}

The structural characteristics were investigated by X-ray diffraction (XRD) by using a $\theta-2 \theta$ diffractometer (D8 Advance, BRUKER) with a monochromatized $\mathrm{Cu} K_{\alpha 1}$ wavelength ( $\lambda=1.54056 \AA$ ) and a texture diffractometer (D8 Discover, BRUKER) giving access to the $\theta-2 \theta, \omega-$ scan and $\varphi$-scan modes. The surface morphology was observed at $10 \mathrm{kV}$ by scanning electron microscopy (SEM, JSM 7100F, JEOL) coupled with an energy dispersive X-ray spectroscopy detector (EDS, SDD X-Max 50mm², Oxford Instruments) to determine the thin film composition. A $5 \mathrm{~nm}$-thick carbon layer was deposited before SEM observation to ensure optimal element detection and especially the potassium element detection that we have observed to be highly sensitive to charge accumulation effect. Each film thickness was measured by SEM on a transverse section obtained from a fracture along an edge.

\subsection{KNN microwave devices}

The dielectric characteristics and the frequency tunability of the KNN thin films were investigated using coplanar waveguide (CPW) devices designed with a 3-D commercial electromagnetic software (Ansys $\operatorname{HFSS}^{\mathrm{TM}}$ ). Three $50-\Omega$ transmission lines $(8 \mathrm{~mm}, 5 \mathrm{~mm}$ and $3 \mathrm{~mm}$ long) with a width $w_{l}=40 \mu \mathrm{m}$ surrounded by a gap $g_{l}=50 \mu \mathrm{m}$ (Figure 1 ) were implemented to retrieve the KNN dielectric characteristics, namely the dielectric permittivity $\varepsilon_{r}$ and the loss tangent tan $\delta$, from the microwave measurements. A CPW quarter-wavelength open-ended stub resonator was also designed to operate in $X$-band (Figure 1). Its resonance frequency $F_{r}$ depends upon the stub length $L_{r}$ and the effective permittivity $\varepsilon_{\text {eff }}$ of the heterostructure, as follows: 


$$
F_{r}=\frac{c}{4 L_{r} \sqrt{\varepsilon_{e f f}}}
$$

where $c$ is the speed of light in vacuum. The devices were fabricated from a $2 \mu \mathrm{m}$-thick silver overlayer / 5 nm-thick titanium underlayer deposited by RF magnetron sputtering at room temperature. The silver thickness is three times larger than the skin depth value $(\delta=0.64 \mu \mathrm{m})$ at $10 \mathrm{GHz}$. Note that the ultra-thin titanium film is used here only to ensure the strong adhesion of the silver metallization onto the ferroelectric oxide. Standard photolithography and wet etching processes were implemented to pattern the devices. Gold wire bondings (15 $\mu$ m-diameter and $250 \mu$ m-length) were used to enforce the equipotential condition on both CPW grounds and prevent from the excitation of parasitic slotline mode.

Microwave measurements at room temperature were carried out through a probe station coupled to a vector network analyzer (VNA 8510C, Hewlett Packard) from $1 \mathrm{GHz}$ to $20 \mathrm{GHz}$ under an external $D C$ bias voltage range from $0 \mathrm{~V}$ to $150 \mathrm{~V}$, which corresponds to a maximal static electric field $E_{\text {bias }}$ equal to $80 \mathrm{kV} / \mathrm{cm}$ for the stub resonator and $27 \mathrm{kV} / \mathrm{cm}$ for the transmission lines. The measured gap dimensions $\left(g_{r} \approx 18 \mu \mathrm{m}\right.$ and $\left.g_{l} \approx 54 \mu \mathrm{m}\right)$ are slightly larger than the nominal ones (Figure 1) due to the inherent overetching of the wet etching process used. Further details are reported elsewhere [29]. 

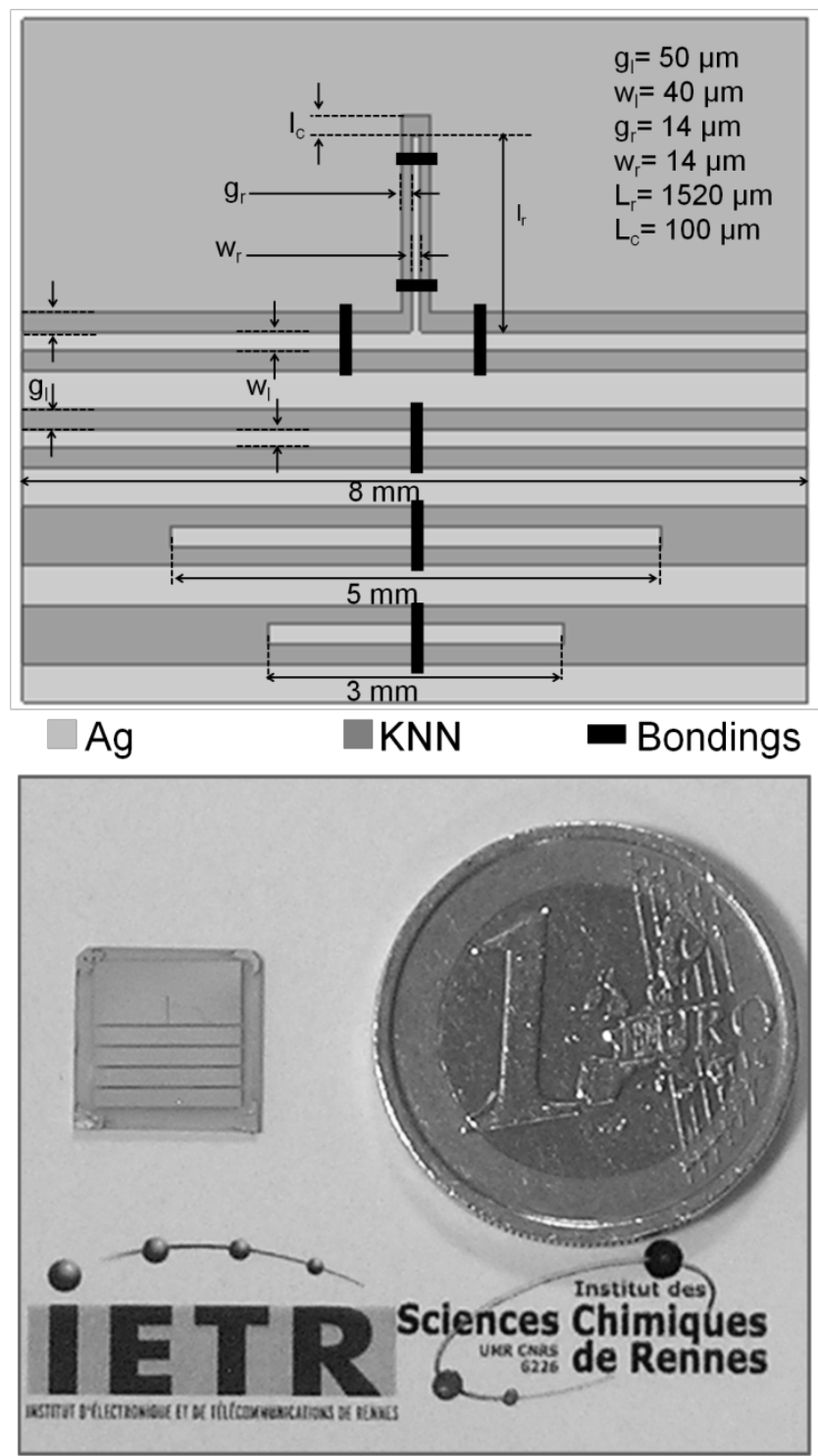

Fig. 1 Layout, dimensions and picture of the CPW devices

\section{Results and discussion}

3.1. Composition, microstructure and structural properties of the KNN thin films

The volatility of potassium, which is higher than that of sodium [30], greatly influences the global stoichiometry of the thin films at the end of the deposition process. Consequently, as described in the experimental details section, the two home-made targets have been K-enriched. The EDS analyses of the targets and of the related thin films (Table 1) depict this volatility. Even after a strong enrichment of the target, the $\mathrm{K}_{0.5} \mathrm{Na}_{0.5} \mathrm{NbO}_{3}$ thin film may exhibit a slight lack of 
alkaline elements with a ratio of $(\mathrm{K}+\mathrm{Na}) / \mathrm{Nb}$ typically in the range $\sim 0.95-1$. This lack of alkaline elements may lead to an oxygen deficiency for charge compensation. The related oxygen vacancies may be responsible for decreasing the piezoelectric and dielectric properties in some ferroelectric oxides [31]. Here, the reported compositions are average values obtained from three measurements performed on different areas of each sample. The achievement of a standard deviation lower than $2 \%$ is affording evidence tending to prove the good homogeneity and reproducibility of the deposition method used. Nevertheless the overall accuracy of EDS technique itself is usually considered close to $10 \%$, especially in the case of resistive materials in thin films. These results enable us to confirm the so-called KNN50/50 thin film composition close to $\mathrm{K}_{0.5} \mathrm{Na}_{0.5} \mathrm{NbO}_{3}$ and that of the KNN70/30 thin film close to $\mathrm{K}_{0.7} \mathrm{Na}_{0.3} \mathrm{NbO}_{3}$.

Figure 2 displays the regular morphology of the thin films. The homogeneous shape of the grains and their arrangement suggest a preferred orientation. Some outgrowths currently observed at the surface of thin films deposited by PLD, especially with not highly densified targets, are visible with a lateral size that is still submicronic. The KNN50/50 sample exhibits a thickness slightly lower than the targeted value: $510 \mathrm{~nm}$ against $\sim 600 \mathrm{~nm}$ (Figure 2a) in contrast with the KNN70/30 sample which presents a thickness equal to $780 \mathrm{~nm}$ (Figure 2b). The thickness difference between the two compositions has been systematically obtained with other samples (not shown here).

\begin{tabular}{|c|c|c|c|c|}
\hline Sample & $\begin{array}{c}\text { Composition ratio } \\
\text { of the targets } \\
(\mathbf{K}: \mathbf{N a}: \mathbf{~ N b})\end{array}$ & $\begin{array}{c}\text { Composition ratio } \\
\text { of the thin films } \\
\mathbf{( K : ~ N a : ~ N b )}\end{array}$ & $\begin{array}{c}\text { Thin film } \\
\text { thickness }(\mathbf{n m})\end{array}$ & $\begin{array}{c}\text { Cell parameters } \\
\mathbf{( \AA )})\end{array}$ \\
\hline KNN50/50 & $0.9: 0.5: 1$ & $0.51: 0.47: 1$ & 510 & $\begin{array}{c}a_{m} \approx c_{m} \approx 4.00 \\
b_{m} \approx 3.95\end{array}$ \\
\hline KNN70/30 & $1.4: 0.3: 1$ & $0.71: 0.29: 1$ & 780 & $\begin{array}{c}a_{m} \approx c_{m} \approx 4.02 \\
b_{m} \approx 3.96\end{array}$ \\
\hline
\end{tabular}

Table 1 Composition, thickness and measured cell parameters of the thin films versus the target composition 


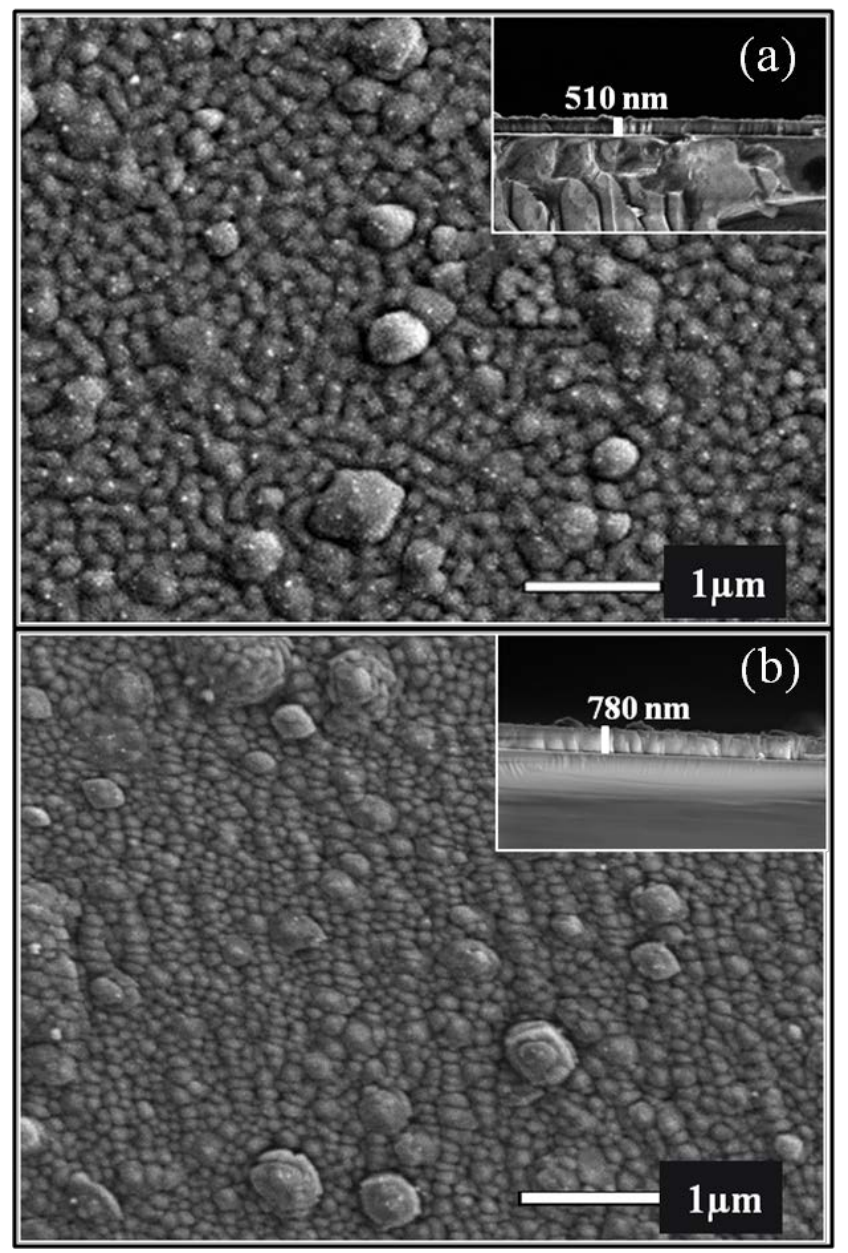

Fig. 2 SEM images of the surface morphology and cross-sections (in inset) of (a) KNN50/50 and (b) KNN70/30 thin films

The XRD patterns of the KNN50/50 and KNN70/30 samples are depicted in Figures 3a and 3b using the monoclinic indexation and displayed with a logarithmic intensity scale. A powder XRD pattern available from the database (JCPDS file \# 00-061-0315) is displayed as reference in Figure 3c [18]. It is worth noting that deficiency in alkaline elements often leads to the presence of the unwanted $\mathrm{K}_{4} \mathrm{Nb}_{6} \mathrm{O}_{17}$ phase (JCPDS file \# 01-076-0977), leading to a peak at $2 \theta \approx 10^{\circ}$ on XRD patterns [32]. For our samples, all the peaks are purely indexed in the KNN phase, demonstrating the absence of such secondary phases. The two peaks at $2 \theta \approx 22^{\circ}$ correspond to the diffraction of the (100) and (010) KNN planes. A strong (100) orientation is observed on both KNN50/50 and KNN70/30 films with a second weaker (110) orientation at $2 \theta \approx 32^{\circ}$. The relative intensities of the (100), (010) and (110) peaks are similar for both samples. The orientation factors of the (100) peak, 
computed by the Lotgering method [33], comparing the relative intensity of the peaks from the experimental XRD patterns (Figures 3a and 3b) to the powder XRD patterns available from the database, are equal to 0.93 and 0.90 for the KNN50/50 and KNN70/30 films, respectively. Therefore both samples can be considered as structurally alike. The slight shift of the KNN70/30 $2 \theta$ peaks towards large angles is attributed to the lattice parameters increase with $\mathrm{K}$ amount increase in the compounds (Table 1). These results are in agreement with the cell parameter values reported by Tellier et al. and Hondoko et al. of $a_{m}=4.004 \AA$ and $c_{m}=3.944 \AA$ for $\mathrm{K}_{0.5} \mathrm{Na}_{0.5} \mathrm{NbO}_{3}$, and $a_{m}=4.01 \AA$ and $c_{m}=3.97 \AA$ for $\mathrm{K}_{0.7} \mathrm{Na}_{0.3} \mathrm{NbO}_{3}[18,19]$.
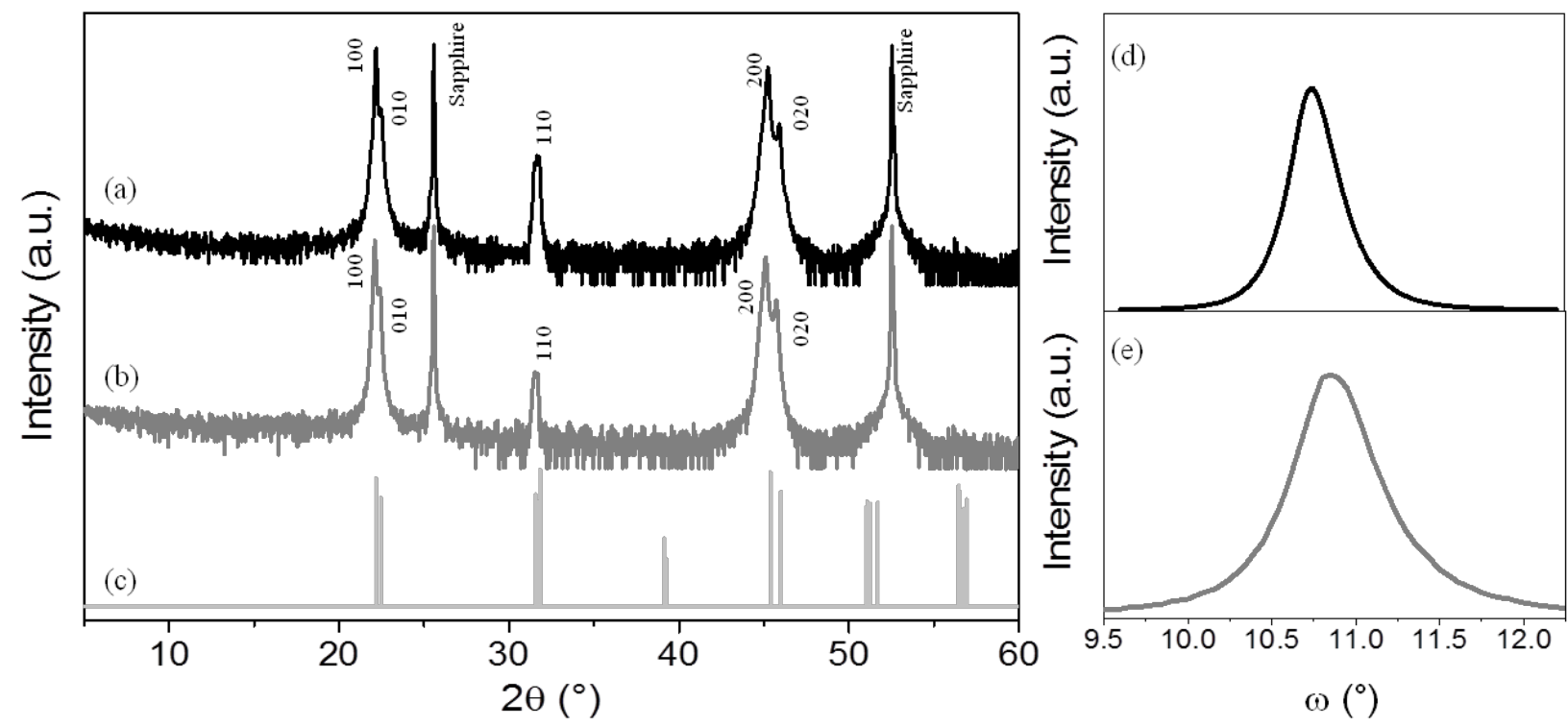

Fig. $3 \Theta-2 \Theta$ X-ray diffraction patterns displayed with a logarithmic intensity scale of (a) KNN50/50 thin film, (b) KNN70/30 thin film (c) $\mathrm{K}_{0.5} \mathrm{Na}_{0.5} \mathrm{NbO}_{3}$ powder retrieved from the database JCPDS file \# 00-061-0315 [18]; $\omega$-scans on the (100) peak of (d) KNN50/50 and (e) KNN70/30 thin films

To further investigate the crystalline quality of the samples, $\omega$-scans on the (100) peak (Figures 3d and 3e) were recorded. The full-width-at-half-maximum (FWHM) is equal to $0.36^{\circ}$ and $0.60^{\circ}$ for the KNN50/50 and KNN70/30 samples, respectively. Those values are a good indication of the well-textured thin films. The $\omega$-scan on the (11) for comparison. The $\varphi$-scans were also performed on the KNN $\{110\}$ planes (Figure 4). They present four distinctive peaks at $90^{\circ}$ apart from one another, which indicate an in-plane ordering 
which refers to an epitaxial-like growth for this orientation, besides a significant background noise corresponding to the texture. This result is in good agreement with the microstructure previously observed by SEM (Figures 2a and 2b). Though examples of epitaxial growth of perovskite on sapphire exist $[34,35]$, such crystalline growth was unexpected due to the large mismatch between the KNN perovskite phase and the R-plane sapphire ( 14\%) and, at our knowledge, has not been reported yet.

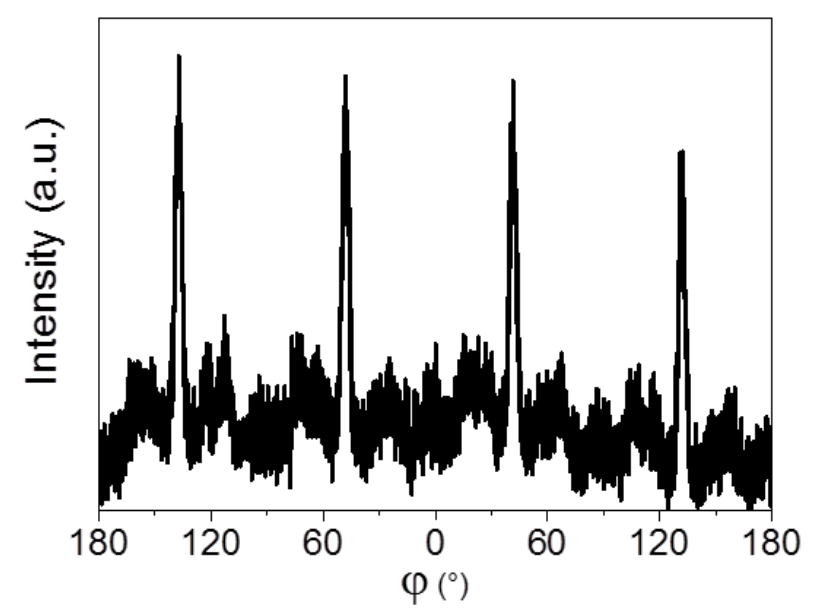

Fig. $4 \varphi$-scans performed on the KNN \{110\} planes typical of KNN50/50 and KNN70/30 thin films deposited on sapphire substrate

\subsection{KNN dielectric characteristics}

The dielectric characteristics $\left(\varepsilon_{r}, \tan \delta\right)$ of the KNN thin films were retrieved from the measured reflection $\left(S_{11}\right)$ and transmission $\left(S_{21}\right)$ coefficients of the CPW transmission lines (Figure 5) [29, 36]. Without biasing, KNN50/50 exhibits a permittivity value $\varepsilon_{r}=360$ at $10 \mathrm{GHz}$ against 250 for KNN70/30. Permittivity value of KNN50/50 is higher than those previously reported on $\mathrm{Dy}_{2} \mathrm{O}_{3}$-doped $\mathrm{KNN}$ thin films $\left(\varepsilon_{r}=307\right.$ at $10 \mathrm{GHz}$ [37]) and on pure $\mathrm{K}_{0.5} \mathrm{Na}_{0.5} \mathrm{NbO}_{3}$ thin films grown on $\mathrm{Pt} / \mathrm{Ti} / \mathrm{SiO}_{2} / \mathrm{Si}\left(\varepsilon_{r}=287\right.$ at $10 \mathrm{GHz}$ [25]). The higher permittivities measured in the present study can be attributed to the crystalline orientation, i.e. epitaxial-like growth, of our samples, compared with the KNN polycrystalline growth mentioned by Peddigari et al. [25]. The loss is also 
higher than that expected for this kind of materials: $\tan \delta=0.36$ for KNN50/50 and $\tan \delta=0.43$ for KNN70/30 without biasing at $10 \mathrm{GHz}$, whereas Peddigari et al. reported tan $\delta=0.014$ at $10 \mathrm{GHz}$ for the $\mathrm{Dy}_{2} \mathrm{O}_{3}$-doped $\mathrm{KNN}$ thin films [37] and $\tan \delta=0.010$ at $10 \mathrm{GHz}$ for the annealed $\mathrm{KNN}$ thin films [25]. As PLD technique induces outgrowths into KNN thin films (Figures 2a and 2b), the interface quality between the metallic transmission lines and the KNN films may have an impact on the retrieved $\tan \delta$ values. This contribution to the measured loss, not present in the split post dielectric resonator (SPDR) [38] technique, could explain the $\tan \delta$ values measured in the present study. Indeed our results can be compared with those reported by Kim et al. [26], i.e. $\tan \delta=0.23$ at $20 \mathrm{GHz}$ measured on a coplanar interdigitated capacitor. Under $E_{\text {bias }}=27 \mathrm{kV} / \mathrm{cm}$, the dielectric permittivity decreases from 360 to 320 for KNN50/50 and from 250 to 220 for KNN70/30 at $10 \mathrm{GHz}$, demonstrating the tunability of such compositions under biasing. The important decrease of the dielectric permittivity from 1 to $5 \mathrm{GHz}$ with and without biasing is attributed to the freezing of the polar domain motion, whereas $\tan \delta$ fluctuations in this frequency range are attributed in part to the metal skin depth loss [29]. 


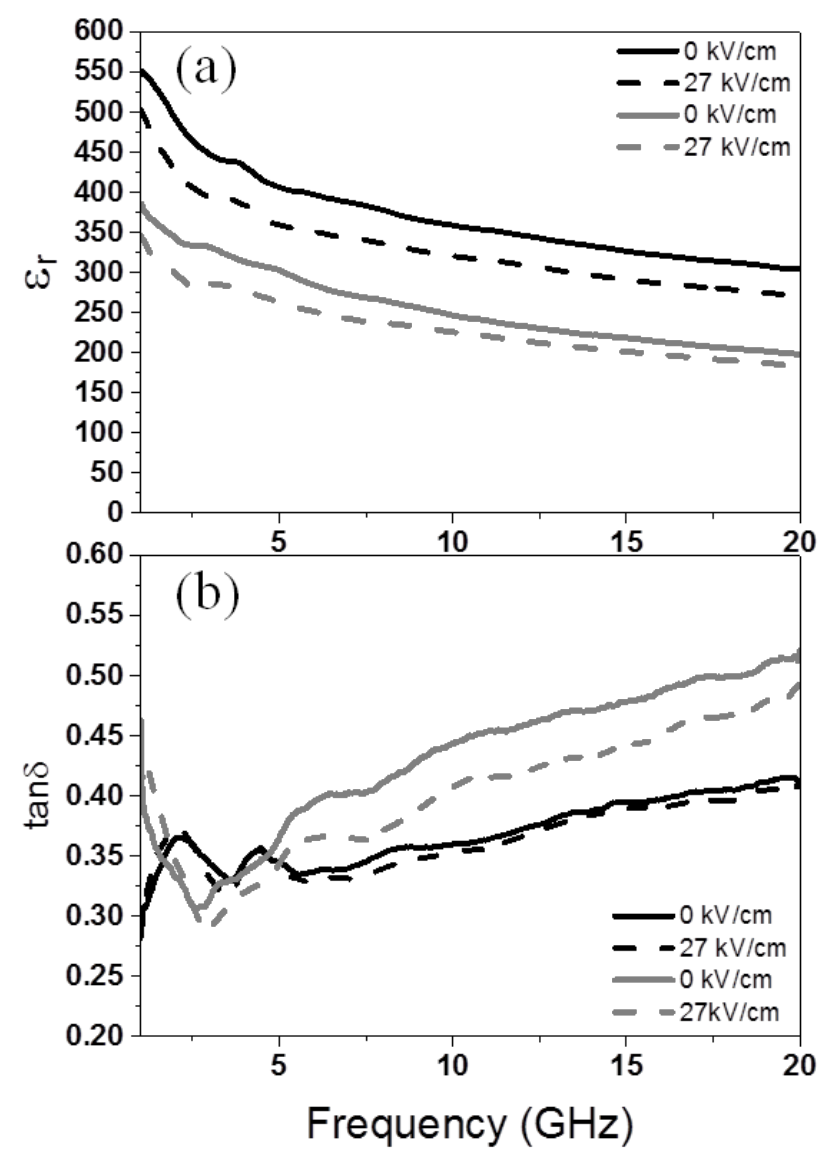

Fig. 5 Measured frequency dependence of (a) dielectric permittivity $\varepsilon_{r}$ and (b) intrinsic loss $\tan \delta$ with and without biasing; Black line: KNN50/50; Grey line: KNN70/30

Resonance frequencies $F_{r}$ (frequency value at the minimum $S_{21}$, see Figure 6 ) of the CPW stub resonators printed on the KNN50/50 and KNN70/30 samples were measured under various bias voltage values. The fine tuning of the KNN dielectric permittivity value under bias voltage controls $F_{r}$. The frequency tunability $T$ (Figure 7 ) is computed from the $F_{r}$ values under $E_{b i a s}$, as follows:

$$
T(\%)=\frac{\left|F_{r}\left(E_{\text {bias }}=0\right)-F_{r}\left(E_{\text {bias }}\right)\right|}{F_{r}\left(E_{\text {bias }}=0\right)} \times 100
$$

The maximum external $D C$ electric field applied is $E_{\text {bias }}=80 \mathrm{kV} / \mathrm{cm}$. The shift of the resonance frequency from $12.7 \mathrm{GHz}$ (without biasing) to $14.6 \mathrm{GHz}$ ( $\mathrm{E}_{\text {bias }}$ max.) and from $12.0 \mathrm{GHz}$ (without biasing) to $13.4 \mathrm{GHz}$ ( $\mathrm{E}_{\text {bias }}$ max.) leads to a frequency tunability equal to $15 \%$ and $12 \%$ for the KNN50/50 and KNN70/30 samples, respectively. More detailed results on tunability values under 
various bias voltages are reported in Figure 7. Clearly the highest tunability is reached with the KNN50/50 sample, especially when the applied bias voltage is high.

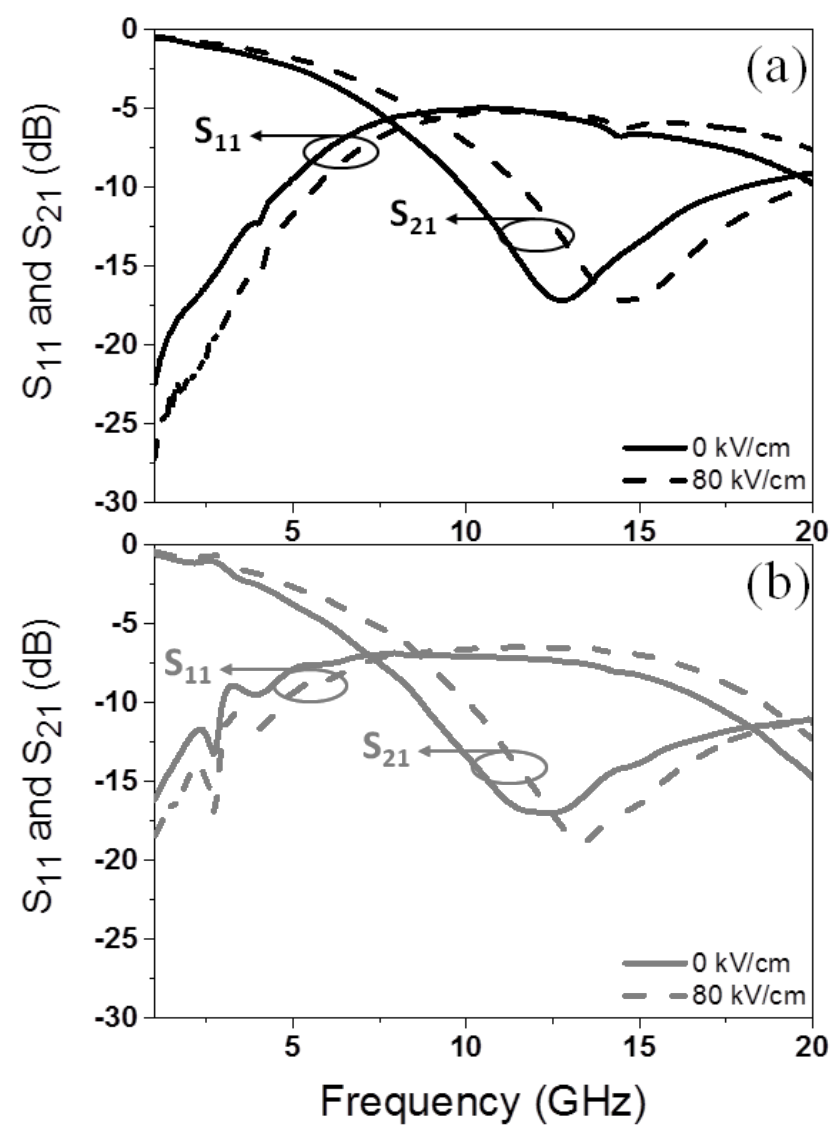

Fig. 6 Measured reflection coefficient $S_{11}$ and transmission coefficient $S_{21}$ with and without biasing on the stub resonator printed on (a) KNN50/50 and (b) KNN70/30

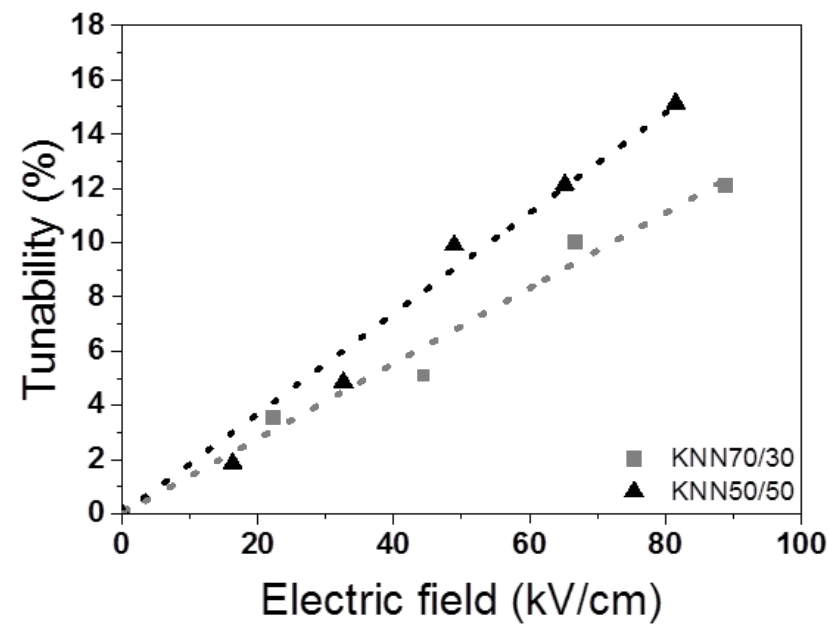

Fig. 7 Frequency tunability under biasing. $\Delta$ KNN50/50; $\square$ KNN70/30; the black and grey dotted lines are guide eyes 
The global loss (GL) of the resonant devices was also computed from $S_{11}$ and $S_{21}$ magnitude values at their specific resonance frequency $F_{r}$, as follows:

$$
G L=1-\left|S_{11}\right|^{2}-\left|S_{21}\right|^{2}
$$

$G L$ is plotted in Figure 8 from 1 to $20 \mathrm{GHz}$ with and without $E_{\text {bias }}$ for both samples. The computed values without biasing for KNN50/50 $(G L=0.59)$ and $\mathrm{KNN70/30}(G L=0.76)$ are of the same order of magnitude, with a slightly higher value for KNN70/30. The decrease of GL under biasing (Table 2) is consistent with the related loss $\tan \delta$ decrease for the KNN 70/30 sample. Regarding the KNN50/50 one, $\tan \delta$ steadiness under biasing explains the non-variation of the $G L$.

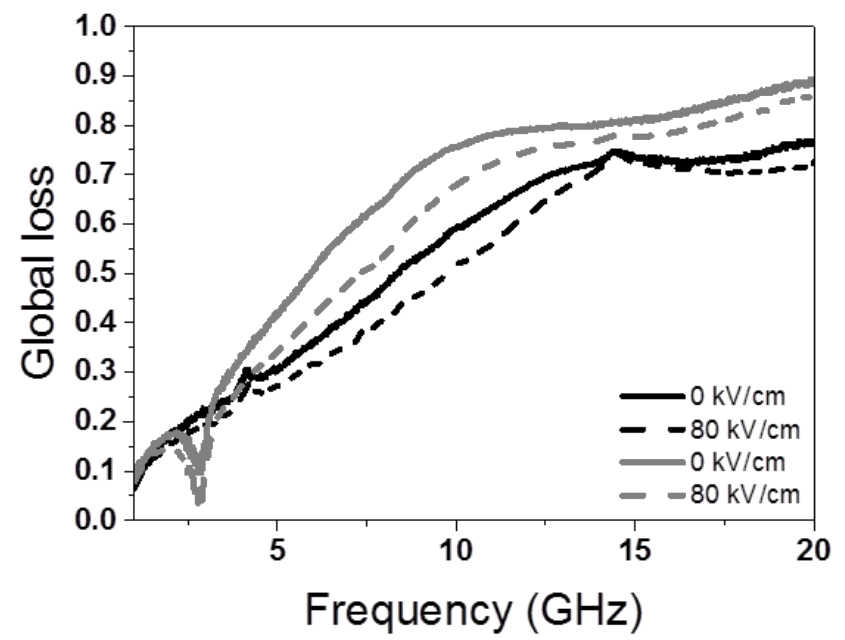

Fig. 8 Global loss variation versus frequency with and without biasing; Black line: KNN50/50; Grey line: KNN70/30

\begin{tabular}{|c|c|c|c|c|c|c|c|}
\hline \multirow[b]{2}{*}{ Sample } & \multicolumn{3}{|c|}{$E_{\text {bias }}=0 \mathrm{kV} / \mathrm{cm}$} & \multicolumn{2}{|c|}{$E_{\text {bias }}=27 \mathrm{kV} / \mathrm{cm}$} & \multirow{2}{*}{$\begin{array}{c}E_{\text {bias }}=80 \mathrm{kV} / \mathrm{cm} \\
G L\end{array}$} & \multirow{2}{*}{$\begin{array}{c}E_{\text {bias }}=80 \mathrm{kV} / \mathrm{cm} \\
T(\%)\end{array}$} \\
\hline & $\varepsilon_{r}$ & $\tan \delta$ & $G L$ & $\varepsilon_{r}$ & $\tan \delta$ & & \\
\hline KNN50/50 & 360 & 0.36 & 0.59 & 320 & 0.35 & 0.51 & 15 \\
\hline KNN70/30 & 250 & 0.43 & 0.76 & 220 & 0.40 & 0.68 & 12 \\
\hline
\end{tabular}

Table 2 Dielectric permittivity $\varepsilon_{r}$, loss tangent $\tan \delta$, and tunability $T$ of the KNN50/50 and KNN70/30 samples at $10 \mathrm{GHz}$; global loss GL is computed at the stub resonator resonance frequency

An additional factor, other than composition, could induce the higher global loss exhibited by the KNN70/30 sample. Indeed, we have observed in a previous work that the use of a thicker ferroelectric film increases comparatively the global loss [39]. Therefore the global loss achieved on 
the 780 nm-thick KNN70/30 sample is consistent with that of the 510 nm-thick KNN 50/50. On the other hand, the frequency tunability is usually enhanced by a thicker film [39], contrasting with the results obtained here, which supports an effect due to the composition. The similar crystalline characteristics of both samples (see section §3.1) point also the discussion at the KNN composition itself. KNN50/50 with a composition close to the morphotropic phase boundary provides advanced performance, especially higher dielectric permittivity and higher frequency tunability at microwave frequencies ( $\varepsilon_{r}=360$ at $10 \mathrm{GHz}$ and $T=15 \%$ ). This value of tunability, while lower than that reported by Kim et al. ( $T=22 \%[26])$ is relevant in regards to the moderate biasing used ( $E_{\text {bias }}=$ $80 \mathrm{kV} / \mathrm{cm}$ against $200 \mathrm{kV} / \mathrm{cm}$ in [26]). This tunability can also be compared with that reported in the $\mathrm{KTa}_{x} \mathrm{Nb}_{1-x} \mathrm{O}_{3}(\mathrm{KTN})$ system, which from a chemical point of view, remains close to that of the KNN system. Even though lower, the result is still relevant considering the KNN Curie temperature $\left(T_{c} \approx\right.$ $400^{\circ} \mathrm{C}$ ) and therefore the greater thermal stability at room temperature that is expected. For comparison, the highest frequency tunability of the KTN-based devices ( $T=44 \%$ under $E_{\text {bias }}=70$ $\mathrm{kV} / \mathrm{cm}$ at $\sim 10 \mathrm{GHz}$ [29]) was obtained with a composition marked by a Curie temperature close to room temperature $\left(T_{c} \approx 90^{\circ} \mathrm{C}\right)$, improving thereby its reconfigurability but also its sensitivity to temperature variation.

Nevertheless, some attempts need to be undertaken to decrease further KNN loss. Previous solutions have already been investigated on ferroelectric oxide materials, such as doping [40], crystalline quality improvement by the use of seed layer [41], extrinsic loss decrease by the use of ferroelectric/dielectric multilayers [42], as well as confining the ferroelectric layer in the efficient regions of the microwave devices [43].

\section{Conclusion}

This study presents the elaboration, the dielectric characterization and the performance at microwave frequencies of tunable ferroelectric KNN devices based on two compositions, namely 
$\mathrm{K}_{0.5} \mathrm{Na}_{0.5} \mathrm{NbO}_{3}$ and $\mathrm{K}_{0.7} \mathrm{Na}_{0.3} \mathrm{NbO}_{3}$. It has been shown that structurally ordered thin films of KNN perovskite on R-plane sapphire are achievable and greatly reproducible with different compositions using PLD technique. The highly oriented films with some in-plane order suggest an epitaxial-like growth, despite the strong mismatch between the two lattices $(\sim 14 \%)$. The characterization of the KNN films at microwave frequencies demonstrates the higher performance at room temperature of the $\mathrm{K}_{0.5} \mathrm{Na}_{0.5} \mathrm{NbO}_{3}$ composition, close to the morphotropic phase boundary. A dielectric permittivity $\varepsilon_{r}=360$ at $10 \mathrm{GHz}$ without biasing associated with a frequency tunability $T=15 \%$ under a moderate bias voltage promotes the strong interest of such films as lead-free ferroelectric material for future tunable microwave devices.

\section{Acknowledgment}

The authors are grateful for the financial support of the Direction Générale de l'Armement (DGA) and the Région Bretagne (PhD research Grant of B.A, project ARMin). This work was also supported by the European Union through the European Regional Development Fund (ERDF), the Ministry of Higher Education and Research, the Région Bretagne, the Département des Côtes d'Armor and Saint-Brieuc Armor Agglomération, through the CPER Projects 2015-2020 MATECOM and SOPHIE / STIC \& Ondes. ScanMAT, UMS 2001 CNRS-University of Rennes 1, received a financial support from the Région Bretagne, the Département d’Ille et Vilaine and the European Union (CPER-FEDER 2007-2014, Présage Nos. 39126 and 37339, and CPER SCANMAT 2015-2020). C. Derouet is warmly acknowledged for technical assistance for X-Ray diffraction.

\section{References}

1. Polla DL (1995) Microelectromechanical systems based on ferroelectric thin films. Microelectron Eng 29:51-58 . doi: 10.1016/0167-9317(95)00114-X

2. Muralt P (2000) Ferroelectric thin films for micro-sensors and actuators: a review. J Micromechanics Microengineering 10:136-146 . doi: 10.1088/0960-1317/10/2/307 
3. Östling M, Koo S-M, Zetterling C-M, Khartsev S, Grishin A (2004) Ferroelectric thin films on silicon carbide for next-generation nonvolatile memory and sensor devices. Thin Solid Films 469-470:444-449 . doi: 10.1016/j.tsf.2004.09.030

4. Setter N, Damjanovic D, Eng L, Fox G, Gevorgian S, Hong S, Kingon A, Kohlstedt H, Park NY, Stephenson GB, Stolitchnov I, Taganstev AK, Taylor DV, Yamada T, Streiffer S (2006) Ferroelectric thin films: Review of materials, properties, and applications. J Appl Phys 100:051606 . doi: 10.1063/1.2336999

5. Chang K, Hsieh L-H (2004) Microwave ring circuits and related structures, $2^{\text {nd }}$ ed. J. Wiley, Hoboken, N.J

6. Cruickshank DB (2011) Microwave materials for wireless applications. Artech House, Boston; London

7. Petosa A (2012) An overview of tuning techniques for frequency-agile antennas. IEEE Antennas Propag Mag 54:271-296 . doi: 10.1109/MAP.2012.6348178

8. Gevorgian S (2009) Ferroelectrics in microwave devices, circuits and systems. Springer London, London

9. Li H-Y, Chen H-P, Chen S-C, Tai C-H, Fu J-S (2012) A tunable slot loop antenna using interdigitated ferroelectric varactors. Antennas and Propagation Society International Symposium (APSURSI), 2012 IEEE:1-2 . doi: 10.1109/APS.2012.6348537

10. Bedair SS, Pulskamp JS, Meyer CD, Mirabelli M, Polcawich RG, Morgan B (2012) Highperformance micromachined inductors tunable by lead zirconate titanate actuators. IEEE Electron Device Lett 33:1483-1485 . doi: 10.1109/LED.2012.2207700

11. Qiu JX, Judy DC, Pulskamp JS, Polcawich RG, Kaul R, Crowne F (2009) Characterization of nonlinear behavior in a tunable phase shifter using ferroelectric PZT thin-film capacitors and its effect on system performance. Microwave Symposium Digest, 2009. MTT '09. IEEE MTTS International:341-344 . doi: 10.1109/MWSYM.2009.5165703

12. Rödel J, Jo W, Seifert KTP, Anton E-M, Granzow T, Damjanovic D (2009) Perspective on the development of lead-free piezoceramics. J Am Ceram Soc 92:1153-1177 . doi: 10.1111/j.1551-2916.2009.03061.x

13. Li J-F, Wang K, Zhu F-Y, Cheng L-Q, Yao F-Z (2013) (K,Na)NbO ${ }_{3}$-based lead-free piezoceramics: Fundamental aspects, processing technologies, and remaining challenges. J Am Ceram Soc 96:3677-3696 . doi: 10.1111/jace.12715

14. Wu J, Xiao D, Zhu J (2015) Potassium-sodium niobate lead-free piezoelectric materials: Past, present, and future of phase boundaries. Chem Rev 115:2559-2595 . doi: 10.1021/cr5006809

15. Egerton L, Dillon DM (1959) Piezoelectric and dielectric properties of ceramics in the system potassium-sodium niobate. J Am Ceram Soc 42:438-442 . doi: 10.1111/j.11512916.1959.tb12971.x

16. Megaw HD, Wells $\mathrm{M}$ (1958) The space group of $\mathrm{NaNbO}_{3}$ and $\left(\mathrm{Na}_{0.995} \mathrm{~K}_{0.005}\right) \mathrm{NbO}_{3}$. Acta Crystallogr 11:858-862 . doi: 10.1107/S0365110X58002437 
17. Ahtee M, Glazer AM (1976) Lattice parameters and tilted octahedra in sodium-potassium niobate solid solutions. Acta Crystallogr Sect A 32:434-446 . doi: 10.1107/S0567739476000983

18. Tellier J, Malic B, Dkhil B, Jenko D, Cilensek J, Kosec M (2009) Crystal structure and phase transitions of sodium potassium niobate perovskites. Solid State Sci 11:320-324 . doi: 10.1016/j.solidstatesciences.2008.07.011

19. Handoko AD, Goh GKL (2010) Hydrothermal synthesis of sodium potassium niobate solid solutions at $200^{\circ} \mathrm{C}$. Green Chem 12:680 . doi: 10.1039/b923840a

20. Shirane G, Newnham R, Pepinsky R (1954) Dielectric properties and phase transitions of $\mathrm{NaNbO}_{3}$ and (Na,K)NbO . Phys Rev 96:581-588 . doi: 10.1103/PhysRev.96.581

21. Saito Y, Takao H, Tani T, Nonoyama T, Takatori K, Homma T, Nagaya T, Nakamura M (2004) Lead-free piezoceramics. Nature 432:84-87 . doi: 10.1038/nature03028

22. Abadei S, Cho C-R, Grishin A, Gevorgian S (2001) Low frequency characterisation of laser ablation deposited thin $\mathrm{Na}_{0.5} \mathrm{~K}_{0.5} \mathrm{NbO}_{3}$ (NKN) films for microwave application. Ferroelectrics 263:173-179 . doi: 10.1080/00150190108225195

23. Gao L, Zhou W, Luo F, Zhu D, Yang Z (2016) Microwave dielectric properties of potassium sodium niobate ceramics with different $\mathrm{K} / \mathrm{Na}$ ratios. Ceram Int 42:19105-19109 . doi: 10.1016/j.ceramint.2016.09.071

24. Gao L, Zhou W, Luo F, Zhu D (2017) Dielectric properties in the microwave range of $\mathrm{K}_{0.5} \mathrm{Na}_{0.5} \mathrm{NbO}_{3}$ ceramics. J Electron Mater 46:123-129 . doi: 10.1007/s11664-016-4853-2

25. Peddigari M, Sindam B, Raju KCJ, Dobbidi P (2015) Optical and microwave dielectric properties of phase pure $\left(\mathrm{K}_{0.5} \mathrm{Na}_{0.5}\right) \mathrm{NbO}_{3}$ thin films deposited by RF magnetron sputtering. $\mathrm{J}$ Am Ceram Soc 98:1444-1452 . doi: 10.1111/jace.13502

26. Kim J-Y, Grishin AM (2006) Niobate-tantalate thin films microwave varactors. Thin Solid Films 515:619-622 . doi: 10.1016/j.tsf.2005.12.212

27. Tennery VJ, Hang KW (1968) Thermal and X-ray diffraction studies of the $\mathrm{NaNbO}_{3}-\mathrm{KNbO}_{3}$ system. J Appl Phys 39:4749-4753 . doi: 10.1063/1.1655833

28. Ahart M, Somayazulu M, Cohen RE, Ganesh P, Dera P, Mao H, Hemley RJ, Ren Y, Liermann $\mathrm{P}, \mathrm{Wu} \mathrm{Z}$ (2008) Origin of morphotropic phase boundaries in ferroelectrics. Nature 451:545548 . doi: 10.1038/nature06459

29. Simon Q, Corredores Y, Castel X, Benzerga R, Sauleau R, Mahdjoubi K, Le Febvrier A, Députier S, Guilloux-Viry M, Zhang L, Laurent P, Tanné G (2011) Highly tunable microwave stub resonator on ferroelectric $\mathrm{KTa}_{0.5} \mathrm{Nb}_{0.5} \mathrm{O}_{3}$ thin film. Appl Phys Lett 99:092904 . doi: $10.1063 / 1.3626040$

30. Hicks WT (1963) Evaluation of vapor-pressure data for mercury, lithium, sodium, and potassium. J Chem Phys 38:1873-1880 . doi: 10.1063/1.1733889 
31. Ang C, Yu Z, Cross LE (2000) Oxygen-vacancy-related low-frequency dielectric relaxation and electrical conduction in $\mathrm{Bi}_{\mathrm{SrTiO}}$. Phys Rev B 62:228-236 . doi: 10.1103/PhysRevB.62.228

32. Rousseau A, Laur V, Guilloux-Viry M, Tanné G, Huret F, Députier S, Perrin A, Lalu F, Laurent P (2006) Pulsed laser deposited $\mathrm{KNbO}_{3}$ thin films for applications in high frequency range. Thin Solid Films 515:2353-2360 . doi: 10.1016/j.tsf.2006.04.010

33. Lotgering FK (1959) Topotactical reactions with ferrimagnetic oxides having hexagonal crystal structures-I. J Inorg Nucl Chem 9:113-123 . doi: 10.1016/0022-1902(59)80070-1

34. Rousseau A, Laur V, Députier S, Bouquet V, Guilloux -Viry M, Tanné G, Laurent P, Huret F, Perrin A (2008) Influence of substrate on the pulsed laser deposition growth and microwave behaviour of $\mathrm{KTa}_{0.6} \mathrm{Nb}_{0.4} \mathrm{O}_{3}$ potassium tantalate niobate ferroelectric thin films. Thin Solid Films 516:4882-4888 . doi: 10.1016/j.tsf.2007.09.029

35. Peng W, Bouquet V, Députier S, Simon Q, Guilloux-Viry M, Perrin A (2007) Effect of thin $\mathrm{KNbO}_{3}$ seed layers on pulsed laser deposited ferroelectic $\mathrm{KTa}_{0.65} \mathrm{Nb}_{0.35} \mathrm{O}_{3}$ films for microwave tunable application. Integr Ferroelectr 93:126-132 . doi: 10.1080/10584580701756383

36. Carlsson E, Gevorgian S (1999) Conformal mapping of the field and charge distributions in multilayered substrate CPWs. IEEE Trans Microw Theory Tech 47:1544-1552 . doi: 10.1109/22.780407

37. Peddigari M, Patel V, Bharti GP, Khare A, Pamu D (2017) Microwave dielectric and nonlinear optical studies on radio-frequency sputtered $\mathrm{Dy}_{2} \mathrm{O}_{3}$-doped $\mathrm{KNN}$ thin films. J Am Ceram Soc 100:3013-3023 . doi: 10.1111/jace.14846

38. Krupka J (2003) Precise measurements of the complex permittivity of dielectric materials at microwave frequencies. Mater Chem Phys 79:195-198 . doi: 10.1016/S0254-0584(02)00257-2

39. Moussavou A-G (2008) Couches minces ferroélectriques $\mathrm{KTa}_{1-\mathrm{x}} \mathrm{Nb}_{\mathrm{x}} \mathrm{O}_{3}(\mathrm{KTN})$ : Applications à la reconfigurabilité de dispositifs hyperfréquences et des antennes BIE. PHD thesis, Université de Rennes 1

40. Simon Q, Bouquet V, Peng W, Le Floch J-M, Houndonougbo F, Députier S, Weber S, Dauscher A, Madrangeas V, Cros D, Guilloux-Viry M (2009) Reduction of microwave dielectric losses in $\mathrm{KTa}_{1-\mathrm{x}} \mathrm{Nb}_{\mathrm{x}} \mathrm{O}_{3}$ thin films by MgO-doping. Thin Solid Films 517:5940-5942 . doi: 10.1016/j.tsf.2009.04.022

41. Le Floch J-M, Houndonougbo F, Madrangeas V, Cros D, Guilloux-Viry M, Peng W (2009) Thin film materials characterization using TE modes cavity. J Electromagn Waves Appl 23:549-559 . doi: 10.1163/156939309787612293

42. Corredores Y, Le Febvrier A, Castel X, Sauleau R, Benzerga R, Députier S, Guilloux-Viry M, Mekadmini A, Martin N, Tanné G (2014) Study of ferroelectric/dielectric multilayers for tunable stub resonator applications at microwaves. Thin Solid Films 553:109-113 . doi: 10.1016/j.tsf.2013.11.068

43. Corredores Y, Simon Q, Benzerga R, Castel X, Sauleau R, Le Febvrier A, Députier S, Guilloux-Viry M, Zhang L, Tanné G (2014) Loss reduction technique in ferroelectric tunable 
devices by laser microetching. Application to a CPW stub resonator in X-band. IEEE Trans Electron Devices 61:4166-4170 . doi: 10.1109/TED.2014.2360846 